\title{
AVALIAÇÃO E CURRÍCULO: INSTRUMENTOS ESCOLARES PARA FOMENTAR A INCLUSÃO SOCIAL
}

\section{ARTIGO ORIGINAL}

TIRELLO, Márcia Moreira ${ }^{1}$

TIRELLO, Márcia Moreira. Avaliação e Currículo: Instrumentos escolares para fomentar a inclusão social. Revista Científica Multidisciplinar Núcleo do Conhecimento. Ano 04, Ed. 10, Vol. 09, pp. 41-62. Outubro de 2019. ISSN: 24480959, Link de

acesso: https://www.nucleodoconhecimento.com.br/educacao/instrumentos$\underline{\text { escolares }}$

\section{RESUMO}

Esse artigo faz uma reflexão entre a prática pedagógica escolar e a inclusão social. Inicialmente, discute a responsabilidade da escola na formação cidadã e a necessidade que a educação moderna tem em valorizar a diversidade que compõe a sociedade atual. A reflexão central baseia-se no fato de que o processo avaliativo e o currículo trabalhado são importantes ferramentas que a escola dispõe para promover a construção efetiva do conhecimento de todo cidadão, portadores ou não de necessidades especiais. Partindo de referenciais teóricos como Lukesi, Hoffmann e a Lei de Diretrizes e Bases Nacionais, investiga o fazer pedagógico, principalmente em sua dimensão avaliativa, diferenciando as funções diagnóstica, somativa e formativa da avaliação. Propondo uma perspectiva inclusiva que possibilite a interação e valorização da diversidade de saberes, conhecimentos e competências. Propõe ainda o levantamento de estratégias que potencializem o acesso de todos os alunos ao seu

${ }^{1}$ Graduada em Letras Vernáculas pela Universidade do Estado da Bahia (2000), Especialista em Literatura Brasileira pela Universidade do Estado da Bahia (2004) e Mestranda em Ciências da Educação pela The Grendal College And University Unigrendal. 
desenvolvimento cognitivo e interação social, transformando assim a escola em um espaço verdadeiramente inclusivo e democrático.

Palavras-chave: Processo avaliativo, currículo, interação, inclusão social.

\section{INTRODUÇÃO}

No mundo moderno, a globalização, as novas tecnologias e a necessidade de acesso à informação têm gerado uma busca incessante pelo conhecimento como diferencial na formação dos sujeitos. As transformações da linguagem utilizada nos processos de interação e comunicação estão produzindo uma sociedade plural e cada vez mais exigente. Uma vez que não se pode pensar em sociedade plural e formação de sujeitos sem o conceito de educação, a realidade contemporânea exige que a escola acompanhe essas mudanças com uma postura política e pedagógica coerente, capaz de colaborar para a melhoria das condições de vida das comunidades abrangidas pela sua ação. Não cabe mais uma concepção de educação, e consequentemente de escola, que atue de forma isolada de sua comunidade, suas produções culturais e diversidades humanas, ou dissociada das diferentes realidades em que estão inseridos seus sujeitos, mas sim uma concepção que prepare cidadãos aptos a desenvolver, valorizar e respeitar as múltiplas inteligências, habilidades e limitações presentes em cada ser humano.

Mas quem são os sujeitos sociais que compõem esse universo escolar? De que forma o cotidiano da sala de aula, o currículo imposto pelo poder público, os projetos estruturantes desenvolvidos e, principalmente a metodologia avaliativa utilizada estão servindo de aliados para a construção dessa educação que prima pela intervenção e transformação da realidade social? Os projetos político-pedagógicos abarcam a ideia de escola como organismo vivo e intrínseco de um efetivo desenvolvimento do cidadão? Os docentes estão sendo preparados para realizar uma prática de avaliação da aprendizagem pautada na lógica da inclusão construindo assim uma educação democrática? Muitos são os questionamentos. 
Dentre tantas questões importantes do cotidiano escolar, investigar a relação existente entre o processo avaliativo, o currículo exigido e a construção de uma educação verdadeiramente inclusiva, é o objetivo central desse artigo, que tem como principal relevância a possibilidade de interferir na realidade local e global, pois é evidente que compreender essa relação e compartilhar reflexões e experiências é o primeiro passo para se estabelecer uma discussão sobre identidade pessoal e social. Falar de identidade social nos dias atuais, é sinônimo de trazer à superfície dos debates pedagógicos a questão da inclusão de todos os alunos, principalmente daqueles que por muito tempo estiveram à margem do processo de escolarização por apresentarem necessidades especiais, quer sejam elas cognitivas, comportamentais ou físicas.

Não é pretensão aqui nomear ou caracterizar as diversas necessidades especiais do alunado, e sim discutir de que forma o fazer pedagógico, no que tange à composição curricular e ao processo avaliativo, pode funcionar como ferramenta de construção da inclusão social. Discutir os modelos avaliativos que se pautam na lógica da homogeneização e como esses modelos funcionam contrariamente ao respeito às especificidades de cada indivíduo, é o ponto de partida desse artigo.

É possível mensurar o conhecimento? O modelo de educação que está estabelecido na atualidade valoriza o disciplinamento e a transmissão de informações como metas principais e não atende à urgente necessidade de incluir os cidadãos que não se enquadram nas exigências da escola conteudista. Um dos principais instrumentos desse modelo de homogeneização é a forma como a avaliação está instituída na educação de modo geral. Essa avaliação da aprendizagem que mede saberes e conhecimentos observando apenas a habilidade de decorar conceitos e informações não está em consonância ou favorecendo uma proposta de escola para todos, porque não oferece oportunidade para que cada aluno, respeitando seu próprio tempo e característica específica, elabore verdadeiramente seu conhecimento.

A sociedade atual necessita integrar áreas distintas do conhecimento e essa integração precisa abranger o reconhecimento da diversidade de saberes, conhecimentos e competências. O fazer pedagógico, no que se refere à metodologia 
avaliativa e organização do currículo, está pautado em um olhar inclusivo, que respeita as diversas formas de se construir e processar informações? Essa é a pergunta central que permeia e motiva essa reflexão.

O resultado das avaliações, internas e de larga escala como por exemplo a Prova Brasil, precisam funcionar como subsídio para o planejamento e organização do currículo e, principalmente, para a (re)estruturação do fazer pedagógico. Para melhor entender a relação existente entre metodologia avaliativa e inclusão ou exclusão social, faz-se necessário analisar as principais características do modelo de avaliação/currículo que a educação tem adotado. Por isso, inicialmente, serão abordados alguns teóricos e suas definições de avaliação escolar.

\section{DESENVOLVIMENTO}

Tecer um olhar crítico sobre o fazer pedagógico e a inclusão social, exige indagar inicialmente como e porque a escola elege os conteúdos a serem trabalhados e de que maneira verifica o domínio que os alunos têm desses conteúdo. Em uma perspectiva investigativa, é necessário refletir sobre a organização do currículo e os diversos modos de avaliar a aprendizagem. Na instituição escola, o currículo oferece um conjunto de diretrizes que norteiam e sistematizam o processo ensinoaprendizagem. No entanto, ele deve ser compreendido em seu sentido global, o qual é composto por muito mais do que intenções e orientações pedagógicas. O currículo deve abarcar diferentes formas de pensamento, de conhecimento, de (re)produção; precisa transcender os muros da escola, se fazer presente na dimensão do aqui e agora, pois carrega uma constituição histórica, ao mesmo tempo em que é dinâmico, pois deve propor mudanças, diálogos, flexibilização, ou seja, deve ser constituído, organizado e reorganizado nas relações do dia a dia. Não pode ser um conjunto de conteúdos e procedimentos a serem cumpridos dentro de uma só lógica e linearidade, mas sim marcado por indagações e reflexões. Para tanto, o Projeto Político Pedagógico, os projetos estruturantes realizados ao longo do ano letivo e as adaptações do planejamento devem dialogar sempre com a realidade da comunidade escolar e suas necessidades específicas. 
O currículo, de fato, retrata a relação teoria e prática. Relação essa que possibilita o contato com a cultura escolar e a cultura da vida cotidiana. Para Sacristán (2000, p.55), o currículo "agrupa diversas fases da cultura, do desenvolvimento pessoal e social, das necessidades vitais dos indivíduos para seu desempenho em sociedade, aptidões e habilidades consideradas fundamentais". Dentro dessa perspectiva, a escolha e organização do currículo escolar deve estar a serviço de uma educação democrática, inclusiva e que se preocupe não somente com a transmissão de informações ou a quantidade de conteúdo, mas principalmente que promova a valorização da diversidade que existe em cada sujeito envolvido nesse espaço educacional.

Nesse sentido, a prática cotidiana pedagógica, ações e modos de pensar influenciam e são influenciados pelo currículo. Mais uma vez, deve-se compreendê-lo não como um programa pré-estabelecido e estático, mas sempre dinâmico e inacabado. Tornase essencial entender que educadores e educandos são todos sujeitos, que influenciam e fazem parte da construção desse currículo que trabalham e aprendem conjuntamente, e não meros executores ou aprendizes deste. O educador não deve ser alguém que segue um guia de práticas pedagógicas, mas que, ao segui-lo, precisa reconstruir, de acordo com as necessidades e características de cada público, novas práticas, princípios e saberes.

Para Silva e Moreira (2006, p.27), é preciso compreender que "a educação e o currículo não atuam como correias transmissoras de uma cultura produzida em outro local, por outros agentes, mas são partes integrantes e ativas de um processo de criação de sentidos, de significações, de sujeitos".

A tradição crítica em educação nos ensinou que o currículo produz formas particulares de conhecimento e de saberes, que o mesmo produz dolorosas divisões sociais, identidades divididas, classes sociais antagônicas. As perspectivas mais recentes ampliam essa visão: o currículo produz e organiza também identidades culturais, de gênero, de raça e de sexo (...) dessa perspectiva, o currículo não pode ser visto simplesmente como um espaço de transmissão de conhecimentos. Ele está centralmente envolvido naquilo que somos, naquilo que nos tornamos. O currículo produz, o currículo nos produz (...) (SILVA, 2001, p.27). 
Outro aspecto do fazer pedagógico que incide diretamente na construção de um sujeito mediador e inclusivo, é a metodologia avaliativa que a escola utiliza. Pode-se afirmar que, hoje, há certo consenso quanto à compreensão de que a aprendizagem mais importante é aquela que vai além da simples aquisição de informações. Sobre isso Lukesi (2000) comenta que a avaliação só se completa com a possibilidade de indicar caminhos mais adequados e mais satisfatórios para uma ação, que está em curso. Segundo o autor, para avaliar é necessário buscar a melhor face do que será avaliado. Por outro lado, também pode-se dizer que os procedimentos avaliativos utilizados têm sido precários e continuam privilegiando a memorização e os níveis de competência de raciocínio considerados "importantes", em uma clara postura de desvalorização de diferentes habilidades e competências que o sujeito pode apresentar.

No dicionário de Pedagogia, Queiroz apresenta o termo avaliação como:

Apreciação, ação de determinar valor de um trabalho, de uma ação. Consiste na coleta de dados qualitativos e quantitativos; no universo pedagógico, o termo avaliação tem sido empregado para referir-se a: medida de desempenho escolar, procedimento de atribuição de nota, conceito ou aplicação de um instrumento de testagem do aproveitamento escolar - "prova" (QUEIROZ, 2003, p.31).

Em termos legais, entende-se que houve grande avanço na forma de se conceber a avaliação da aprendizagem. A Lei de Diretrizes e Bases da Educação Nacional LDBEN, de 1996, em seu artigo 24, inciso V, alínea a, afirma que a avaliação deve ser "contínua e cumulativa" em relação ao desempenho do aluno, com prevalência dos aspectos "qualitativos sobre os quantitativos" e dos resultados "ao longo do período sobre os de eventuais provas finais". Existe, então, há mais de uma década, uma orientação explícita que expressa uma concepção de avaliação afinada com as modernas teorias que apontam para a natureza sociocultural do desenvolvimento humano. Gadotti (1991) diz que a avaliação é inerente e essencial à educação, e é dela indissociável enquanto concebida como problematização e questionamento da realidade e conduza a uma reflexão sobre a ação. 
Entretanto, mudanças em práticas e concepções não são realizadas apenas pela força da lei, especialmente se essas propostas legais não vêm acompanhadas, de forma coerente, de outras políticas públicas necessárias para a implementação dessas mudanças, tais como políticas claras de valorização do professor, incentivo à formação continuada, análise dos resultados dos exames nacionais para redirecionar o fazer pedagógico, a democratização das gestões escolares, entre muitas outras.

Uma simples observação das práticas avaliativas tal como essas têm sido realizadas, certamente mostraria que sua natureza continua sendo essencialmente classificatória, seletiva e autoritária, privilegiando o resultado em detrimento do processo. Essa realidade se traduz com muita clareza no alto índice de evasão escolar, que ocorre principalmente pelo rótulo de incapacidade que o sistema avaliativo atual coloca em grande parte das crianças e adolescentes brasileiros.

Segundo Foucault (2011), utilizar a prática de exames para "julgar" a capacidade dos sujeitos foi algo construído historicamente. Afirma ainda que a avaliação deve ser uma prática de constituição de sujeitos que pode engendrar domínios de saberes que não somente fazem aparecer novos conceitos, novas técnicas, mas também fazem nascer formas totalmente novas dos sujeitos se relacionarem com seu próprio conhecimento.

É necessário pensar estratégias de ensino para potencializar o acesso de todos os alunos aos conhecimentos que a escola se propõe a trabalhar. Essas estratégias precisam transpor os limites da considerada normalidade (como se apenas um modelo comportamental fosse ideal para todos os seres humanos), impostos por uma suposta elite intelectual e promover a aceitação das diversas maneiras de produzir conhecimento. Para tanto, encarar que cada um precisa de um tempo e motivação diferenciados para elaborar seu próprio saber, deve ser o pilar do processo avaliativo. Não se trata apenas de reconhecer que existem dificuldades cognitivas a serem superadas, mas também entender que os vínculos de interação cognitivo-afetiva podem ser de fato um diferencial nessas estratégias que a escola precisa criar para produzir verdadeiramente a inclusão de todos. 
Nessa linha, o psicólogo israelense Reuven Feuerstein defende a ideia da aprendizagem mediada. Segundo ele, as experiências do sujeito com seu meio funcionam como eixo base no desenvolvimento cognitivo-intelectual; mediações bem elaboradas ajudam a estruturar a elaboração do pensamento (FEUERSTEIN apud GOMES, 2002). Esse conceito de mediação deveria ser o princípio básico estruturante da metodologia avaliativa escolar, uma vez que a função da escola não é transmitir conhecimentos prontos e sim ajudar a desenvolver a capacidade de aprender de cada indivíduo, portador de necessidades especiais ou não.

$\mathrm{Na}$ verdade, o professor mediador precisa considerar a avaliação como instrumento que auxilie o aluno na construção do seu conhecimento, através de questionamentos, informações e reflexões que favoreçam a flexibilização das estruturas mentais, não elaborar provas que exijam nada mais do que decorar conceitos e reproduzir dados. Reuven Feuerstein, com sua Teoria da Modificabilidade Cognitiva, afirma que através de uma mediação adequada, todos podem desenvolver seus esquemas mentais a ponto de vencer inclusive dificuldades cognitivas graves.

Transformar conhecimentos em saberes pressupõe a capacidade de relacionar aqueles com vivências tecidas nas diversas interações sociais que os sujeitos experimentam durante toda sua existência. Dentro dessa lógica, toda forma de avaliação da aprendizagem é arbitrária, uma vez que não se pode pensar em um único instrumento que consiga abarcar todas as probabilidades de produção dos saberes individuais e coletivos.

Descrever o processo avaliativo de cada segmento da educação básica seria tema suficiente para outra pesquisa, mas segundo Hoffmann (1996), no que se refere à função, o ato de avaliar geralmente apresenta três tipos básicos: diagnóstica, formativa e somativa. Em linhas gerais, a Função Diagnóstica pretende avaliar a posição do aluno face às novas aprendizagens que lhe serão propostas e as anteriores. A Função Formativa tem cunho processual, visa a avaliar em que medida os objetivos pretendidos estão efetivamente sendo alcançados por meio das atividades propostas, e em que medida está havendo compatibilidade entre tais objetivos e os resultados. E a Função Somativa está voltada para o resultado da 
unidade de aprendizagem em questão, tendo como objetivo determinar o grau de domínio do aluno em uma área com o propósito de classificar os supostos níveis de aproveitamento.

Segundo Vasconcellos (2000), a forma com que cada um desses tipos de avaliação tem sido utilizado pode variar bastante, podendo combinar-se de diferentes maneiras, não sendo por si só, um adequado e eficiente indicador de uma prática totalmente democrática ou autoritária.

Pode-se dizer, entretanto, que um Projeto Político Pedagógico que use exclusivamente as formas de cunho diagnóstico e somativo estará muito em concordância com uma visão excludente, à medida que não instrumentaliza os participantes do processo, professores e alunos, a avaliarem processualmente suas atuações. Sobre isso, torna-se essencial adotar modificações que são necessárias na organização do trabalho pedagógico para que o processo avaliativo alcance o objetivo formativo. Essas modificações podem abranger tanto a diversidade de ferramentas avaliativas até a observação do crescimento do educando ao longo do processo, através da comparação dos relatórios elaborados pelo professor quanto ao estágio de desenvolvimento alcançado durante o percurso dos ciclos escolares.

Partindo de uma visão sócio-interacionista, e entendendo que a realidade é construída dialeticamente, portanto, está em permanente mudança, é necessário que se discuta a Função Formativa da avaliação. Hoffmann (1996) defende uma prática em que a reciprocidade intelectual possa se desenvolver por meio de um método investigativo sobre as manifestações do educando, a discussão das ideias, a argumentação e contra-argumentação do professor e do aluno, numa reflexão conjunta.

Para ela, a avaliação deve significar a relação entre dois sujeitos que percebem o mundo por meio de suas próprias individualidades subjetivas, sem a precisão de unicamente testar e medir. Nesse sentido, a autora afirma que "não podemos ceder a vez do diálogo aos números em nome da precisão. Assim como não devemos reduzir o processo amplo da avaliação às suas ferramentas. Essas reduções incrementam o jogo do poder na educação" (HOFFMANN, 1996, p.62). 
A avaliação é a reflexão transformada em ação. Ação essa que nos impulsiona a novas reflexões. Reflexão permanente do educador sobre a realidade, e acompanhamento, passo a passo, do educando, na sua trajetória de construção de conhecimento. Um processo interativo, através do qual educandos e educadores aprendem sobre si mesmos e sobre a realidade escolar no ato próprio da avaliação (HOFFMANN, 1996, p.18).

Se a avaliação da aprendizagem deve se dar em um processo interativo, inclusivo e dinâmico, a escola precisa pensar em metodologias avaliativas que não sejam excludentes. Inserir esse processo dentro de uma prática que favoreça a diversidade humana, em seus aspectos cognitivos, comportamentais e físicos, significa desvincular-se dos conceitos de normalidade, de crenças que defendem 0 nivelamento de saberes como se o ser humano possuísse uma receita única de produzir saber e, principalmente buscar estratégias para trabalhar, no cotidiano, com os alunos que apresentam diferentes processos de desenvolvimento cognitivo. Só assim, a ação pedagógica estará de fato a serviço do processo de inclusão social.

Pensar uma educação democrática e inclusiva, pressupõe fomentar a aprendizagem do professor e do aluno. Escola eficiente é aquela cujo Projeto Político Pedagógico se baseia no princípio de que, apesar da escola ser um espaço coletivo, cada ser social que a compõe possui um modo e tempo específicos para aprender. Por isso, a metodologia avaliativa não deve ignorar o caráter processual do desenvolvimento cognitivo; cada um traz experiências próprias, vivências específicas que estão relacionadas ao seu cotidiano familiar e social. Partir do pressuposto de que , apesar de todas essas diferenças, todos os alunos precisam aprender a mesma coisa ao mesmo tempo, seria o mesmo que afirmar que quando eles transpõem as portas da escola, deixam pra trás tudo o que são e passam e ser somente depósitos de conhecimentos que jamais vão produzir saberes verdadeiros, uma vez que não se misturariam com o conhecimento de mundo que cada um tem impresso em si mesmo.

\section{CONSIDERAÇÕES FINAIS}

O grande desafio dessa temática, é refletir sobre as ações pedagógicas que respeitem a forma única que cada sujeito tem de dar sentido ao currículo que é trabalhado pela 
escola, e principalmente construir um processo avaliativo que reconheça que existem caminhos, processos e tempos muito diferentes que constituem o desenvolvimento cognitivo. Em uma mesma sala de aula pode-se observar alunos em diferentes estágios de amadurecimento intelectual, afetivo, físico, comportamental e cognitivo. Não se trata de não avaliar, mas sim de entender que os alunos que não se encaixam no modelo de normalidade, no que diz respeito à aprendizagem dos conteúdos, precisam ser estimulados, desafiados a se superar, cada um com seus instrumentos internos próprios.

Garcia (1999), diz que a avaliação só funciona como dispositivo de inclusão, se a prática pedagógica considerar o erro como hipótese, como uma indicação de como o aluno está construindo as relações entre os conteúdos trabalhados e sua realidade. Para tanto, as avaliações devem colocar à disposição dos alunos diversas formas para expressarem suas ideias, para testarem suas hipóteses, para verificarem quais delas se concretizam na realidade e quais devem ser descartadas. Essa prática avaliativa que prioriza o processo, derruba a ideia de incapacidade e enfrenta a crença de que alguns alunos não aprendem. Fortalecem o pressuposto que, se respeitados o tempo e os caminhos diferenciados que cada um utiliza para elaborar sentidos, todo aluno pode avançar no processo cognitivo de construção do conhecimento; e esse seria um dos pilares da educação inclusiva.

Segundo Garcia (1999), as três principais características de avaliação de caráter inclusivo é ser: diagnóstica, para observar onde o aluno está no processo de aprendizagem; dinâmica, para acompanhar o desenvolvimento ao longo do processo para escolher as intervenções que melhor ajudem na exploração do potencial existente; e inclusiva à medida que busca novas estratégias de intervenção para auxiliar a resolução de desafios.

Analisar procedimentos avaliativos é uma tarefa complexa, porque desafia algumas concepções preestabelecidas no universo escolar, como exemplo o pressuposto de que o professor é o detentor único do conhecimento, ou que o único objetivo da escola é formar sujeitos competentes no que se refere ao domínio da maior quantidade de informações possível. E educar de forma inclusiva é trilhar um caminho não contrário, 
mas diferente, onde o maior objetivo da escola seja aprender a valorizar significados e comportamentos diversos, aprendendo assim a conviver com o outro em todas as suas especificidades; isso significa também admitir que todos os sujeitos envolvidos nesse processo ensino-aprendizagem estão em contínua caminhada de desenvolvimento, em constante transformação dos seus conhecimentos em saberes, particulares e coletivos.

Segundo Touraine (1999), conviver com as diferenças nos ensina a ver o outro e nós mesmos como sujeitos, e para construir essa política de convivência é necessário partir do pressuposto de que cada um pode exercer o seu direito de ser sujeito de forma diversa, única e ao mesmo tempo integrada com o outro.

Essa perspectiva de educação inclusiva obrigatoriamente sugere um conjunto de procedimentos que favoreçam o constante aprendizado tanto do professor quanto do aluno, pois qualquer melhoria da aprendizagem discente passa naturalmente, não mecanicamente, pela aprendizagem docente. Melhorar a qualidade do ensino pressupõe buscar novas formas de comunicar, integrar e fomentar a construção do conhecimento de todos os sujeitos sociais envolvidos no ambiente escolar.

Dentro desse objetivo de incluir indivíduos que não estão moldados à ideia de "normalidade cognitiva", torna-se indispensável um olhar muito mais atento às particularidades e individualidades que nos tornam sujeitos de nossa própria existência. E na escola, os Projetos Políticos Pedagógicos, o currículo trabalhado e a metodologia avaliativa utilizada são peças fundamentais para viabilizar a construção de um convívio social harmonioso, inclusivo e efetivamente integrador.

\section{REFERÊNCIAS}

FOUCAULT, Michel. Microfísica do Poder. Tradução de Roberto Machado. 29aํ ed. Rio de Janeiro: Edições Graal, 2011.

GADOTTI, M. Uma escola para todos os caminhos da autonomia escolar. Petrópolis: Vozes, 1991. 
GARCIA, Carlos. Formação de professores. Para uma mudança educativa. Porto: Porto Editora,1999.

GOMES, Cristiano Mauro Assis. Feuerstein e a Construção Mediada do Conhecimento. Porto Alegre: Artmed, 2002.

HOFFMANN, J. Avaliação: Mito e desafio. Porto Alegre: Mediação, 1996. . Lei $n^{\circ} 9.394$, de 20 de dezembro de 1996. Estabelece as diretrizes e bases da educação nacional. Diário Oficial da república federativa do Brasil, Brasília, DF, 23 dez. 1996.

LUCKESI, P. C. O que é mesmo o ato de avaliar a Aprendizagem. Revista Novas Perspectivas em Avaliação, Porto Alegre, n.12, p. 06-11, Fev-Abril/2000.

SACRISTÁN, J. G. O currículo: uma reflexão sobre a prática. Porto Alegre: Artmed 2000.

SILVA, T. T. O currículo como fetiche: a poética e a política do texto curricular. Belo Horizonte: Autêntica, 2001.

. MOREIRA, Antônio Flávio (org.) Currículo, Cultura e Sociedade. 9ª ed. São Paulo: Cortez, 2006.

TOURAINE, Alain. Poderemos viver juntos: iguais e diferentes. Petrópolis: Vozes, 1999.

QUEIROZ, Tânia Dias. Dicionário Prático de Pedagogia. São Paulo: Rideel, $1^{\underline{a}}$ ed. 2003.

VASCONCELOS, C. S. Avaliação: concepção dialética-libertadora do processo de avaliação escolar. São Paulo: Libertad, 2000.

Enviado: Setembro, 2019.

Aprovado: Outubro, 2019. 